\title{
A STUDY ON PORTFOLIO CONSTRUCTION BY CONSIDERING FUNDAMENTAL ANALYSIS AND USING SHARPE'S SINGLE INDEX MODEL: INDIAN CONTEXT
}

\begin{tabular}{|l|l|l|}
\hline Mr. Dileep S & Dr. G.V. Kesava Rao. & Dr. M D Sai Baba \\
Assistant Professor, & Professor \& Dean - R\&D. & Professor, Department of \\
Department of Management & Department of MBA \& Research & Management Studies, Dayananda \\
Studies, Dayananda Sagar & Centre R.N.S. Institute of & Sagar Academy of Technology and \\
Academy of Technology and & Technology Bangalore 560 098. & Management \\
Management & $\underline{\text { drgvkr@gmail.com }}$ & Bangalore 560 082 \\
Bangalore 560 082 & & saibaba_11084@yahoo.com \\
dileepudupi@gmail.com & & \\
\hline
\end{tabular}

\section{Abstract}

The past few decades of world's new financial order have brought in full liberalization in general and on the front of financial markets in particular, it has led to the emerging market experiacing unparallel capital inflows since 1990. This paper is an effort to look into if the Shape's Single Index Model holds in the case of the emerging market of the world. The study covers forty sector in Indian (over 1120 companies) considered three companies in each sector i.e. 120 companies and six year (2009-2014) data choosen for the study. The result of the study indicates that, there are 58 companies as per the model selection and testing these companies for periods of two months to check the feasibility of the model. Since the results are positive for the test period, so can be conclude that Sharpe's Single Index Model holds strong in Indian Capital Market.

Key Words: Capital Market, Sharpe Single Index Model, Portfolio constraction.

\section{PORTFOLIO}

A portfolio consists of any combination of assets and / or securities, the outcome of which cannot be defined with certainty. A portfolio goes with a saying that " $A$ wise man never puts all his eggs in one basket". Since it is rarely desirable to invest the entire funds of an individual or an institution in a single security one should always consider investing in a portfolio. It is essential that every security be viewed as a part of portfolio. Two basic principles of finance form the basis for portfolio theory, namely, Time value of money and the Safety of money.
Portfolio theory is based on two assumptions. All other things remaining the same-

1. Investors prefer higher rate of return to a lower rate of return, and

2. Investors are risk averse, i.e., would like to avoid risk.

The traditional portfolio managers diversified their funds over a large number of securities to strike a balance between risk and return. However this was done on the basis of their intuition without really understanding the magnitude of risk reduction. The 1950's saw a body of knowledge being developed, which measured the expected rate of return and 
risk associated with combining assets. This study came to be known as Portfolio Theory. Portfolio Management is a process that encompasses many activities of investment in assets and securities. It is a dynamic and flexible concept that involves continuous and systematic analysis, judgment and operations. The objective of portfolio management is to help the investors to maximize their returns for a given level of risk appetite. Portfolio Management is an art and requires high degree of expertise. It is essentially a systematic method of managing one's investment efficiently.

The five phases of portfolio management are 1.Security Analysis 2.Portfolio Analysis, 3.Portfolio Selection, 4.Portfolio Revision and 5.Portfolio Evaluation.

\section{WILLIAM SHARPE'S SINGLE INDEX MODEL}

"There are two elements of security returnsindependent and dependent". The basic notion underlying the single index model is that the movements in stock market affect all stocks. Casual observation of share prices reveals that when the market moves up, prices of most shares tend to increase when the market goes down the prices of most shares tend to decline. William Sharpe assumed that, for the sake of simplicity, the return on security could be regarded as being linearly adapted to a single index like the market index.

Theoretically, the market index should consist of all the securities trading in the market. However a popular average can be treated as a surrogate for the market index.
Acceptance of idea of a market index, Sharpe argued, would obviate the need for calculating thousands of co -variances between individual securities in the single underlying factor being measured by the market index. Hence, this model has come to be known as "The Market Model" or "Single Index Model".

Every investor faces the dilemma, as to which scrip to select for his portfolio in order to get adequate return. Besides, the investor has to decide how much to invest in each scrip. Simple Sharpe Portfolio optimization model enables the investor to find a portfolio that best meets the goals objectives and risk tolerance of the investor. The method also stresses on portfolio optimization, which is an important component of the portfolio selection process. It helps in selecting a set of scrips, which provides the highest rate of return for the lowest risk that the investor is willing to undertake.

\section{LITERATURE REVIEW}

J. Francis Mary and G. Rathikathe have found that in their paper "Single Index Model and the Construction Of optimal portfolio with CNXPHARMA scrip" risk and return plays an important role in making any investment decisions. Decision include Investment should be done or not and which securities should be included in portfolio. Determining efficient portfolios within an asset class (e.g., stocks) can be achieved with the Single index (beta) model proposed by Sharpe. Sharpe's single-index model was applied by using the monthly closing prices 
of 10 companies listed in NSE and CNX PHARMA price index for the period from September 2010 to September 2014. From the empirical analysis it can be concluded that out of 10 companies only one company is selected for investment purpose on the basis of Cut-off point which was -0.11182 .

Apurva A Chauhan identified that portfolio management is the crucial decision for any investor. It is important to decide where to invest and how much to invest. The present study focuses on constructing the optimal portfolio with the help of Sharpe Single Index model. Sharpe Single index model uses various inputs such as excess return to beta ratio, unsystematic risk, market return and variance etc to construct the optimal portfolio. In present study, portfolio is constructed from stocks of CNX nifty. Data is collected from top ten companies of CNX nifty based on their weights for the time period of August 2014. Out of 10 stocks, 4 stocks are selected for investing namely State Bank of India, Tata Motors Ltd, Housing Development Finance Corporation Ltd, Reliance Industries Ltd. Sharpe model suggest investors to invest major portion of their money $(54.14 \%)$ in State Bank of India.

\section{NEED FOR THE STUDY:}

Financial consultant and academicians engaged in business research always need to advise new financial management tools. The new performance evaluation techniques and concepts helpsto bring trancperencyin the financial and non-financial system in the corporate world. Today investors also need to be focused on different tools and models. The investor must understand concepts and relevance of Sharpe's Single Index Model, which provides unique insight to value creation.

\section{OBJECTIVES OF THE STUDY}

1. To identify the best performance of the companies and selecting three companies from each of the selected forty sectors based on Return on Equity.

2. To construct an optimal portfolio empirically using the Sharpe's Single Index Model

3. Testing the model for a period of two months i.e. Jan-2015 and Feb-2015.

\section{SCOPE OF THE STUDY:}

The study has been conducted most popular forty sector as specified by covering period from January 2009 to Dec 2014 (six year) consisting of daily observations. The purpose selecting daily observation as sample is to have better estimate of beta coefficient, because returns are calculated using long time period (i.e. monthly or yearly) might result in changes of beta over the examined period introducing biases in estimates. Risk free rate of return is considered based on 30 years Government bond rate.

\section{METHODOLOGY}

The data used in this project is of secondary nature. The data is collected from secondary sources such as various websites, journals, newspapers, books, etc. The analysis used in 
this project has been done using selective technical tools. In Equity market, risk is analyzed and trading decisions are taken on basis of technical analysis. It is collection of share prices of selected companies for a period of six years.

a. Type of Study - The research conducted is an analytical study. In this project the study is conducted to construct a portfolio based on past five years data using the tools like ROE, Sharpe Single Index Model.

b. Type of Data - Data required for this study was secondary data which was collected from various secondary sources like Capital Line Database, BSE, Ministry of Banking, Investopedia, Economy Watch etc.

c. Sample Size - The sample consists of 40 sectors of the BSE selected from the website of Edelweiss Financial Services Ltd.

\section{d. Hypothesis}

Ho: The linear assumption of the Single Index Model does not necessarily hold good in Indian Capital Market.

H1: The linear assumption of the Single Index Model always holds good in Indian Capital Market.

\section{ANALYSIS}

Table - 1: Testing of portfolio's performance for two months (Jan-2015 and Feb-2015) by considering Rs.1 Crore.

\begin{tabular}{|l|l|l|l|l|l|l|l|}
\hline Rank & Company & $\begin{array}{l}\text { Weight } \\
\text { \% }\end{array}$ & $\begin{array}{l}\text { Price on } \\
\text { Jan 1st }\end{array}$ & $\begin{array}{l}\text { Price on } \\
\text { Jan 31st }\end{array}$ & $\begin{array}{l}\text { Profit } \\
\text { /Loss }\end{array}$ & $\begin{array}{l}\text { Price on } \\
\text { 27th Feb }\end{array}$ & Profit /Loss \\
\hline $\mathbf{0}$ & Sensex & & $\mathbf{2 7 5 0 7 . 5 4}$ & $\mathbf{2 9 1 8 2 . 9 5}$ & & $\mathbf{2 9 2 2 0 . 1}$ & \\
\hline 1 & Hind.Composites & $2.5824 \%$ & 1247.2 & 1313.55 & 13738.02 & 1283.50 & 7516.05 \\
\hline 2 & Kovai Medical & $2.2738 \%$ & 488.3 & 669.6 & 84421.90 & 623.00 & 62722.72 \\
\hline 3 & Blue Dart Exp. & $4.1299 \%$ & 6455.95 & 6826 & 23672.30 & 7102.35 & 41350.56 \\
\hline 4 & Page Industries & $6.2717 \%$ & 12299.7 & 11785.75 & -26206.51 & 11538.30 & -38824.08 \\
\hline 5 & Poly Medicure & $2.3635 \%$ & 916.95 & 998.45 & 21007.41 & 494.80 & -108813.25 \\
\hline 6 & MayurUniquote & $2.4564 \%$ & 430.25 & 470.4 & 22922.84 & 433.30 & 1741.34 \\
\hline 7 & Kansai Nerolac & $2.7053 \%$ & 2024.85 & 2428.85 & 53976.58 & 2321.95 & 39694.16 \\
\hline 8 & 3M INDIA & $4.2351 \%$ & 6448.1 & 6793.55 & 22689.01 & 7803.50 & 89022.09 \\
\hline 9 & SreeSakthi Paper Mills & $0.6520 \%$ & 13.9 & 16.85 & 13837.68 & 16.95 & 14306.76 \\
\hline 10 & Relaxo Footwear & $2.1759 \%$ & 577.8 & 658.9 & 30540.83 & 707.75 & 48936.87 \\
\hline 11 & Garware Polyester & $1.6817 \%$ & 132.65 & 134.5 & 2345.37 & 103.30 & -37208.93 \\
\hline 12 & P I Inds. & $1.0000 \%$ & 536.1 & 498.85 & -6948.53 & 593.85 & 10772.56 \\
\hline 13 & Honeywell Auto & $3.4963 \%$ & 6892.95 & 7342.5 & 22802.41 & 8963.80 & 105039.21 \\
\hline 14 & Indo National & $1.6091 \%$ & 810.65 & 771.3 & -7810.74 & 716.25 & -18737.84 \\
\hline 15 & Savita Oil Tech & $2.2195 \%$ & 731.4 & 733.05 & 500.72 & 601.25 & -39495.88 \\
\hline
\end{tabular}


Asia Pacific Journals

\begin{tabular}{|c|c|c|c|c|c|c|c|}
\hline 16 & Nicco Park and Resorts & $0.6298 \%$ & 18.05 & 16.65 & -4884.88 & 16.00 & -7152.86 \\
\hline 17 & Thermax & $3.4758 \%$ & 1063.15 & 1145.6 & 26955.77 & 1146.85 & 27364.43 \\
\hline 18 & Shree Cement & $6.6229 \%$ & 9366.15 & 10956.45 & 112452.32 & 10976.90 & 113898.36 \\
\hline 19 & Greenply & $1.1411 \%$ & 830 & 935 & 14435.00 & 951.25 & 16668.99 \\
\hline 20 & Cera Sanitary. & $3.3571 \%$ & 1799.55 & 2137.95 & 63128.61 & 2563.55 & 142524.41 \\
\hline 21 & SadbhavEngg. & $0.9403 \%$ & 257.4 & 284.4 & 9863.16 & 316.20 & 21479.76 \\
\hline 22 & Nava Bharat Vent & $0.9742 \%$ & 196.8 & 193.1 & -1831.50 & 189.00 & -3861.00 \\
\hline 23 & Global Offshore & $1.7455 \%$ & 705.5 & 835.8 & 32237.95 & 802.50 & 23999.09 \\
\hline 24 & V-Mart Retail & $0.7719 \%$ & 538.95 & 529.1 & -1410.75 & 581.75 & 6129.95 \\
\hline 25 & $\begin{array}{l}\text { Taneja Aerospace and } \\
\text { Aviation }\end{array}$ & $0.7839 \%$ & 69.2 & 63.35 & -6626.64 & 66.75 & -2775.26 \\
\hline 26 & Apollo Hospitals & $1.4527 \%$ & 1126.2 & 1310.8 & 23812.29 & 1302.75 & 22773.89 \\
\hline 27 & BalkrishnaInds & $1.5133 \%$ & 615.65 & 648.4 & 8049.98 & 600.90 & -3625.56 \\
\hline 28 & Godrej Consumer & $3.1803 \%$ & 965.05 & 1061.6 & 31817.68 & 1145.60 & 59499.55 \\
\hline 29 & HSIL & $2.5669 \%$ & 368.4 & 399 & 21321.10 & 413.65 & 31528.75 \\
\hline 30 & Huhtamaki PPL & $2.4832 \%$ & 186.05 & 206.7 & 27561.2 & 216.7 & 40908 \\
\hline 31 & Global Vectra Helicorp & $0.7151 \%$ & 66.65 & 59.6 & -7564.3 & 47.6 & -20440 \\
\hline 32 & Bosch & $5.8142 \%$ & 19462.5 & 23829.3 & 130451 & 26424.1 & 207968 \\
\hline 33 & Bayer Crop Sci. & $2.9171 \%$ & 3213.1 & 3597.2 & 34871.4 & 3451.9 & 21680 \\
\hline 34 & CESC & $1.1870 \%$ & 662.4 & 729.4 & 12006.5 & 598.85 & -11388 \\
\hline 35 & Godfrey Phillips & $0.3704 \%$ & 591.65 & 590.4 & -78.258 & 479.1 & -7046.4 \\
\hline 36 & Supreme Inds. & $1.5685 \%$ & 590.6 & 592.15 & 411.652 & 658.9 & 18139.2 \\
\hline 37 & AllcargoLogist. & $0.2355 \%$ & 329.3 & 332.65 & 239.539 & 341.9 & 900.954 \\
\hline 38 & Simplex Infra & $0.6343 \%$ & 361.9 & 375.55 & 2392.49 & 423.2 & 10744.3 \\
\hline 39 & PidiliteInds. & $1.8141 \%$ & 549.6 & 569.7 & 6634.66 & 554.3 & 1551.39 \\
\hline 40 & Tube Investments & $1.7233 \%$ & 353.35 & 367.35 & 6828.03 & 355.2 & 902.275 \\
\hline 41 & Emami Paper Mills & $0.1526 \%$ & 47 & 45 & -649.38 & 43.9 & -1006.5 \\
\hline 42 & Akzo Nobel & $2.2795 \%$ & 1382.95 & 1501.15 & 19482.4 & 1478.5 & 15749.1 \\
\hline 43 & CRISIL & $0.5879 \%$ & 1930.45 & 2097.4 & 5084.55 & 2064.55 & 4084.09 \\
\hline 44 & Amara Raja Batt. & $1.6086 \%$ & 817.3 & 860.65 & 8532.26 & 884.6 & 13246.2 \\
\hline 45 & Colgate-Palm. & $2.1146 \%$ & 1806.05 & 1879.75 & 8629.03 & 1919.3 & 13259.7 \\
\hline 46 & MRF & $1.7542 \%$ & 37977 & 39992 & 9307.7 & 41190 & 14841.1 \\
\hline 47 & Guj Gas Company & $0.5252 \%$ & 764.65 & 656.6 & -7421.9 & 586 & -12271 \\
\hline 48 & H D F C & $0.5162 \%$ & 1123.45 & 1265.65 & 6534.04 & 1347.1 & 10276.6 \\
\hline 49 & Jubilant Life & $0.1830 \%$ & 142.3 & 172.7 & 3908.96 & 159.2 & 2173.07 \\
\hline 50 & United Breweries & $0.4947 \%$ & 835.2 & 973.75 & 8206.6 & 1005.55 & 10090.2 \\
\hline 51 & GujFluorochem & $0.3845 \%$ & 757.15 & 724.35 & -1665.5 & 771.3 & 718.499 \\
\hline
\end{tabular}


Asia Pacific Journals

\begin{tabular}{|l|l|l|l|l|l|l|l|}
\hline 52 & Tide Water Oil & $0.3238 \%$ & 18624.9 & 18432.2 & -335 & 16388 & -3888.8 \\
\hline 53 & Asian Paints & $0.1163 \%$ & 750.35 & 857.45 & 1659.6 & 807 & 877.835 \\
\hline 54 & PiramalEnterp. & $0.1848 \%$ & 829.85 & 833.55 & 82.3954 & 907.15 & 1721.39 \\
\hline 55 & AurobindoPharma & $0.1517 \%$ & 1127.5 & 1248.1 & 1623.07 & 1033.3 & -1267.8 \\
\hline 56 & Finolex Cables & $0.1317 \%$ & 262.95 & 253.7 & -463.32 & 272.1 & 458.311 \\
\hline 57 & Ruby Mills & $0.0072 \%$ & 289.65 & 290.3 & 1.60948 & 288.4 & -3.0951 \\
\hline 58 & Oracle Fin Serv & $0.0126 \%$ & 3357.2 & 3391.1 & 12.6888 & 3262.7 & -35.371 \\
\hline
\end{tabular}

\section{Chart showing \% profit for January 2015 and February 2015}

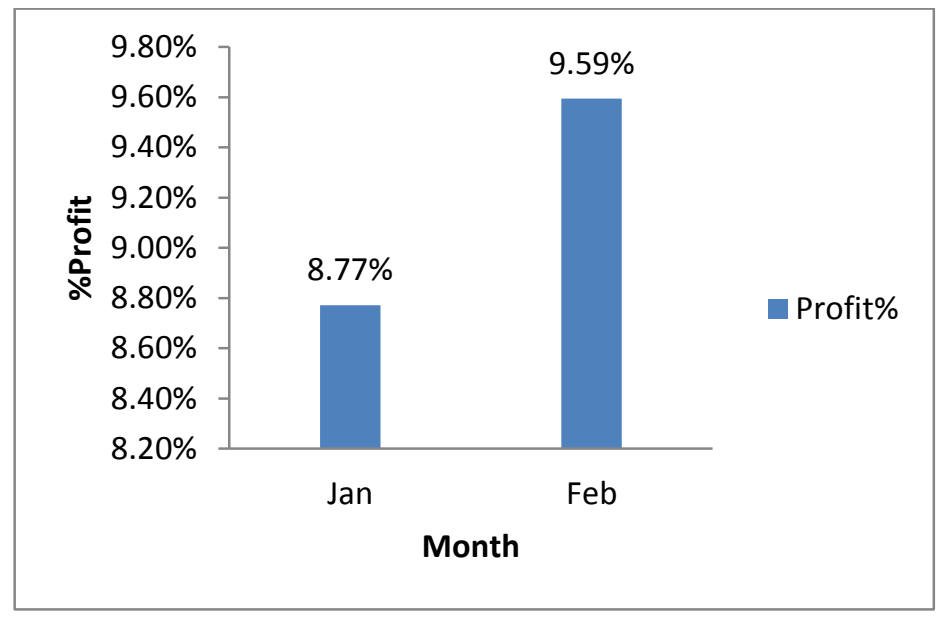

The portfolio constructed using Sharpe's Single Index model is tested for two months. An investment of Rupees 10000000 is made on $1^{\text {st }}$ Jan 2015. On $31^{\text {st }}$ Jan 2015 the portfolio yielded a profit of Rupees 877093 i.e. $8.771 \%$ on investment. Similarly On $27^{\text {th }}$ Feb 2015 the portfolio yielded a profit of Rupees 959418 i.e. $9.594 \%$ on investment. Hence, the Null Hypothesis is rejected and accepted the Alternative hypothesis i.e. The linear assumption of the Single Index Model always holds good in Indian Capital Market.

\section{CONCLUSION}

The study was attempt to gather information about the efficiency of market under the study with the help of applying Sharpe's Single Index Model and test whether the model holds at present in Indian market. The study found that amoung selected of 120 companies through fundamental analysis, Single Index Model identified 58 companies for the portfolio investment. With the help of two months testing cloud resulting that of return. Hence, it may be conclude that Single Index model strongly holds in Indian Capital Market. 


\section{REFERENCE}

[1] J. Francis Mary and G. Rathikathe have found that in their paper "Single Index Model and the Construction Of optimal portfolio with CNXPHARMA scrip, International Journal of Management (IJM), ISSN 0976 - 6502

[2] Apurva A Chauhan , "A Study on Usage of Sharpe's Single Index Model In Portfolio Construction With Reference To Cnx Nifty" Global Journal for Research Analysis, Volume-3, Issue-10, Oct$2014 \cdot$ ISSN No 2277 - 8160

[3] http://info.shine.com/IndustryInformation/Finance-andBanking/117.aspx

[4] http://www.ibef.org/industry/banking .aspx

[5] P. Varadharajan, Dr. P. Vikkraman and $\mathrm{J}$ Joshua Selvakumar. "Construction of Portfolio Using Sharpe Index Model with Reference to FMCC Industry in India" RVMJ Journal of Management Research, Vol. 3 Issue 2 PP 68-75, July- Dec 2011,

[6] Risk-Based Dynamic Asset Allocation with Extreme Tails and Correlation. The Journal of Portfolio Management Summer 2012, Vol. 38, No.4: pp.26-42,

[7] Explanation of Industry Returns Using The Variable Beta Model And Lagged Variable Beta Model, Journal Of Financial And Strategic
Decisions Volume 8 Number 2 Summers 1995. 